\title{
The functional variant rs 334558 of GSK3B is associated with remission in patients with depressive disorders
}

This article was published in the following Dove Press journal: Pharmacogenomics and Personalized Medicine

\author{
Anastasia Levchenkol,* \\ Innokentiy S Losenkov ${ }^{2, *}$ \\ Natalia MVyalova ${ }^{2}$ \\ German G Simutkin ${ }^{2}$ \\ Nikolay A Bokhan ${ }^{2,3}$ \\ Bob Wilffert ${ }^{4,5}$ \\ Anton JM Loonen ${ }^{4,6}$ \\ Svetlana A Ivanova ${ }^{2,7}$
}

'Institute of Translational Biomedicine, Saint Petersburg State University, Saint Petersburg, Russia; ${ }^{2}$ Mental Health Research Institute, Tomsk National Research Medical Center of the Russian Academy of Sciences, Tomsk, Russia; ${ }^{3}$ Department of Psychotherapy and Psychological Counseling, National Research Tomsk State University, Tomsk, Russia; ${ }^{4}$ Groningen Research Institute of Pharmacy, University of Groningen, Groningen, the Netherlands;

${ }^{5}$ University Medical Center Groningen, University of Groningen, Groningen, the Netherlands; ${ }^{6} \mathrm{GGZ}$ Westelijk Noord-Brabant, Bergen op Zoom, the Netherlands; ${ }^{7}$ Division for Control and Diagnostics, School of Non-Destructive Testing \& Security, National Research Tomsk Polytechnic University, Tomsk, Russia

*These authors contributed equally to this work

Correspondence: Anastasia Levchenko Institute of Translational Biomedicine, Saint Petersburg State University, 7/9 Universitetskaya Embankment, Saint Petersburg 199034, Russia

Tel +7 8I23636939

Email a.levchenko@spbu.ru
Purpose: $G S K 3 B$ and $A K T 1$ genes have been implicated in the pathogenesis of a number of psychiatric and neurological disorders. Furthermore, their genetic variants are associated with response to antidepressant pharmacotherapy. As the evidence is still incomplete and inconsistent, continuing efforts to investigate the role of these two genes in the pathogenesis and treatment of brain disorders is necessary. The aim of our study was thus to evaluate the association of variants of these two genes with depressive disorders and drug treatment response.

Patients and methods: In the present study, 222 patients with a depressive disorder who underwent pharmacological antidepressant treatment were divided into remitters and non-remitters following a 28-day course of pharmacotherapy. The association of a depressive disorder and remission rates with polymorphisms rs334558 in the GSK3B gene and rs1130214 and rs3730358 in the $A K T 1$ gene was evaluated with a chi-square test.

Results: Neither of the studied genetic variants was associated with a depressive disorder. Furthermore, frequencies of alleles and genotypes for rs1130214 and rs3730358 were not different in the groups of remitters and non-remitters. However, the activating allele $\mathrm{T}$ of the functional polymorphism rs334558 was significantly associated with remission, when all types of antidepressant drugs were included. This association continued as a trend when only patients taking selective serotonin reuptake inhibitors were considered.

Conclusion: The present study provides support that the functional polymorphism rs 334558 of $G S K 3 B$ may play a role as a useful genetic and pharmacogenetic biomarker in the framework of personalized medicine approach.

Keywords: depressive disorder, association study, $A K T 1, G S K 3 B$, genetic biomarker

\section{Introduction}

Depressive disorders are the third leading cause of disability worldwide, according to a 2015 report. ${ }^{1}$ The phenotype is complex, indicating the existence of numerous types and subtypes, ${ }^{2}$ as are genetic factors contributing to these disorders. ${ }^{3-5}$ Inheritance of one type, major depressive disorder (MDD), is only 30-40\%, as was shown by twin studies. ${ }^{6,7}$ Therefore, environmental factors, translated as epigenetics, must play a substantial role in the etiology. ${ }^{8,9}$ Despite the apparent difficulties in the study of genetics of depressive disorders, there have been some breakthroughs in the last several years. ${ }^{4}$ An apparent reason that replicable results in genetic studies of depressive disorders have been difficult to achieve is that the patients constitute a very heterogeneous group and the most appropriate approach would be to view depressive disorders from the angle of personalized medicine. ${ }^{10-19}$ An example of personalized approach is Research 
Domain Criteria that take account of molecular factors in the pathogenesis of mental illnesses. ${ }^{20-22}$ This approach is particularly relevant, given the fact that, for example, MDD is pharmacotherapy-resistant in $30-40 \%$ of cases. ${ }^{23}$ Indeed, without understanding the precise etiopathological mechanisms in different groups of patients, it will not be possible to treat these disorders efficiently.

An important volume of pharmacogenetic studies of depressive disorders exists, including genome-wide association studies and case-control association studies using candidate genes ${ }^{24-28}$ (pharmacoepigenetics of depressive disorders is also a developing field $\left.{ }^{29}\right)$. One of the candidate genes used in pharmacogenetic studies in psychiatry is $A K T 1$, a gene implicated in the pathogenesis of psychiatric disorders and response to medication via the AKT/GSK3 pathway. ${ }^{28,30-34}$ Single nucleotide polymorphisms (SNPs) rs1130214 and rs3730358 in this gene were investigated in the present study because of association of the TC haplotype with lower protein levels of AKT1, which suggests impaired mRNA expression or processing. ${ }^{34}$ In addition, SNP rs3730358 was found to be associated with late-onset depression. ${ }^{35}$ Another candidate gene is $G S K 3 B$, one of the major regulators of multiple molecular pathways, including $\mathrm{WNT}^{36,37}$ and AKT/ GSK3 pathways. ${ }^{30,32}$ In fact, implication of GSK3B and of its pathways in psychiatric disorders has been extensively investigated. ${ }^{32-34,38-48}$ This gene is directly or indirectly inhibited by antipsychotics, lithium, and antidepressants. ${ }^{30,31}$ The variant rs334558, found in the promoter of $G S K 3 B$, is known to be functional, as it determines the expression level of $G S K 3 B$, possibly by regulating the transcription factor binding to the promoter. ${ }^{49}$ In particular, the allele $\mathrm{T}$ is associated with a 1.4-fold increased transcriptional strength, compared to the ancestral allele $\mathrm{C}$, apparently because the nucleotide $\mathrm{T}$ creates a new binding site at the promoter for the transcription factor AP4.

In the present study, we report the association of remission following pharmacological antidepressant treatment with the functional SNP rs334558. Other SNPs and phenotypes showed no association.

\section{Patients and methods Study subjects}

The study was carried out in accordance with The Code of Ethics of the World Medical Association (Declaration of Helsinki 1975, revised in Fortaleza, Brazil, 2013) for experiments involving humans. After approval of the study protocol by the Local Bioethics Committee of the Mental Health Research Institute in Tomsk, Russia (Siberian region), 222 patients were recruited from an inpatient facility of the same institute. One hundred and twenty-seven control subjects without psychiatric disorders were also recruited into the study. Only subjects of European ancestry were considered. All subjects gave written informed consent after a proper explanation of the prospective study.

In particular, we included patients with a depressive disorder, determined using the following diagnostic criteria of the International Statistical Classification of Diseases and Related Health Problems, 10th Revision (ICD-10): depressive episode (ICD-10: F32, 44.4\%), recurrent depressive disorder (ICD-10: F33, 34.4\%), bipolar disorder (ICD-10: F31, 15.3\%), and dysthymia (ICD-10: F34.1, 2.9\%). The available demographic data comprised age (18-70 years or $49.93 \pm 10.76$ years), gender (177 women and $45 \mathrm{men}$ ), education (university $43.8 \%$, professional college $44.4 \%$, secondary school $11.8 \%$ ), employment (employed $68.4 \%$, unemployed or retired $31.6 \%$ ), and marital status (married $53.2 \%$, widowed $19.3 \%$, divorced $17 \%$, single $10.5 \%$ ).

Clinical and demographic data were initially recorded in hard-copy medical files by psychiatrists at the Department of Affective Disorders of the Mental Health Research Institute in Tomsk, and this work was supervised by Dr. German Simutkin. These collected data were then transferred to a digital file (an electronic database) and were extracted from it during our study.

During their follow-up in the clinic, patients were given several different groups of antidepressants: selective serotonin reuptake inhibitors (SSRIs) (escitalopram, fluoxetine, paroxetine, fluvoxamine, sertraline, citalopram) $(57.9 \%$ of patients), tricyclic antidepressants (clomipramine, pipofezine) $(20.0 \%)$, serotonin-norepinephrine reuptake inhibitors (duloxetine, venlafaxine) (7.1\%), noradrenergic and specific serotonergic antidepressants (mirtazapine, mianserin) (2.7\%), and agomelatine (12.3\%). All antidepressants were used in recommended average therapeutic doses. The duration of treatment was not less than 28 days. For definition of remission, Hamilton Depression Rating scale 17 items (HDRS-17) ${ }^{50}$ was used. The evaluation was made on the 28 th day of treatment. Remitters were identified if the HDRS-17 scores were $\leq 7$.

\section{Genotyping}

Evacuated blood collection tubes "Vacutainer" (Becton Dickinson, Franklin Lakes, NJ, USA) with EDTA as the anticoagulant were used. Extraction of DNA from whole venous blood was performed using the phenol-chloroform method. Concentration and purity of DNA were measured 
using NanoDrop 8000 UV-Vis (ultraviolet-visible) spectrophotometer (Thermo Fisher Scientific, Waltham, MA, USA).

SNPs rs334558 of the GSK3B gene and rs1130214 and rs3730358 of the $A K T 1$ gene were genotyped by polymerase chain reaction (PCR) using the fluorogenic 5'-exonuclease TaqMan technology and the real-time PCR system "StepOnePlus” (Applied Biosystems, Foster City, CA, USA).

\section{Statistical procedures}

Statistical analyses were performed using SPSS software, V 20.0 (IBM Corporation, Armonk, NY, USA) for Windows. Pearson's chi-square test was used for the between-group comparison of genotypic and allelic frequencies at significance level $\alpha=0.05$. Deviation from Hardy-Weinberg equilibrium of genotypic frequencies was also calculated with a chi-square test.

\section{Results}

Of the three SNPs tested, none were associated with depressive disorders when genotypes and alleles were compared between cases and controls. Association was significant only for the SNP rs334558, constituted by alleles $\mathrm{T}$ and $\mathrm{C}$, when the group of remitters was compared to non-remitters, for all pharmacological classes of medication taken together. Allele $\mathrm{T}$ was found to be associated with remission after 28 days of treatment. In particular, genotypes and alleles were different between remitters and non-remitters, at $p=0.049$ and $p=0.015$, respectively (odds ratio [OR] genotype $\mathrm{T} / \mathrm{T}$ $=2.49$, 95\% CI: $0.98-6.30$; OR allele $\mathrm{T}=2.19$, 95\% confidence interval $[\mathrm{CI}]: 1.01-4.75)$. There was no deviation from Hardy-Weinberg equilibrium in the groups of remitters and non-remitters. Table 1 shows these results.

We also measured the association separately for the SSRI group, a class of medication used by the greatest proportion of patients in the cohort. Results of comparison between remitters and non-remitters, shown in Table 2, were significant, at $p=0.039$, only when alleles were compared, but not genotypes (OR genotype $\mathrm{T} / \mathrm{T}=3.05,95 \% \mathrm{CI}$ : 0.83-11.22; OR allele $\mathrm{T}=2.37,95 \% \mathrm{CI}$ : 0.82-6.86). The same as for all classes of medication taken together, in the SSRI group remission was associated with allele $\mathrm{T}$.

\section{Discussion}

Previous studies presented apparently conflicting results for rs334558, some reporting association of neurological and psychiatric phenotypes, such as Parkinson's disease, Alzheimer's disease, bipolar disorder, schizophrenia, adverse reaction to medication tardive dyskinesia, and resistance to treatment in the case of MDD and bipolar disorder, with the activating allele $\mathrm{T}^{49,51-59}$ while others identified allele $\mathrm{C}$ as potentially pathogenic in the case of Alzheimer's disease and multiple sclerosis. ${ }^{60,61}$ Meta-analyses similarly reported either allele T associated with Alzheimer's disease and MDD, ${ }^{62,63}$ or allele $\mathrm{C}$ associated with schizophrenia. ${ }^{64}$

Table I Distribution of alleles and genotypes of GSK3B and AKTI polymorphisms in groups of remitters and non-remitters

\begin{tabular}{|c|c|c|c|c|c|}
\hline $\begin{array}{l}\text { Polymorphism, } \\
\text { allele frequencies (\%)* }\end{array}$ & $\begin{array}{l}\text { Genotype, } \\
\text { allele }\end{array}$ & Remitters (\%) & $\begin{array}{l}\text { Non- } \\
\text { remitters (\%) }\end{array}$ & $\begin{array}{l}\text { Hardy-Weinberg } \\
\text { equilibrium }\left(\chi^{2}, p\right)\end{array}$ & $\chi^{2}, p$ \\
\hline \multicolumn{6}{|l|}{ GSK3B } \\
\hline & $\mathrm{T} / \mathrm{T}$ & 31.1 & 15.8 & $\chi_{1}^{2}=0.082, p_{1}=0.775 ; \chi_{2}^{2}=$ & $\chi^{2}=6.022, p=0.049$ \\
\hline rs334558 & $\mathrm{C} / \mathrm{T}$ & 50.3 & 50.0 & $0.139, p_{2}=0.709$ & \\
\hline $\mathrm{T}=71.2$ & $\mathrm{C} / \mathrm{C}$ & 18.6 & 34.2 & & \\
\hline \multirow[t]{2}{*}{$C=28.8$} & $\mathrm{~T}$ & 56.3 & 40.8 & & $\chi^{2}=5.919, p=0.015$ \\
\hline & C & 43.7 & 59.2 & & \\
\hline \multicolumn{6}{|l|}{$A K T I$} \\
\hline & $\mathrm{G} / \mathrm{G}$ & 47.3 & 55.0 & $\chi_{1}^{2}=1.384, p_{1}=0.239 ; \chi_{2}^{2}=$ & $\chi^{2}=1.366, p=0.505$ \\
\hline rsII302I4 & $\mathrm{G} / \mathrm{T}$ & 40.0 & 30.0 & $3.265, p_{2}=0.071$ & \\
\hline $\mathrm{G}=72.2$ & $\mathrm{~T} / \mathrm{T}$ & 12.7 & 15.0 & & \\
\hline \multirow[t]{3}{*}{$\mathrm{T}=27.8$} & $\mathrm{G}$ & 67.3 & 70.0 & & $\chi^{2}=0.219, p=0.640$ \\
\hline & $\mathrm{T}$ & 32.7 & 30.0 & & \\
\hline & $\mathrm{C} / \mathrm{C}$ & 72.7 & 65.0 & $\chi_{1}^{2}=0.539, p_{1}=0.463 ; \chi_{2}^{2}=$ & $\chi^{2}=1.150, p=0.563$ \\
\hline rs3730358 & $\mathrm{C} / \mathrm{T}$ & 24.2 & 32.5 & $0.178, p_{2}=0.673$ & \\
\hline$C=80.8$ & $\mathrm{~T} / \mathrm{T}$ & 3.0 & 2.5 & & \\
\hline \multirow[t]{2}{*}{$\mathrm{T}=19.2$} & C & 84.8 & 81.2 & & $\chi^{2}=0.625, p=0.429$ \\
\hline & $\mathrm{T}$ & 15.2 & 18.8 & & \\
\hline
\end{tabular}

Notes: Numbers I and 2 in subscript represent group of remitters and group of non-remitters, respectively. $*$ The allele frequencies are in the reference population of 198 Utah (USA) residents with Northern and Western European ancestry, as listed in the 1000 Genomes Project, Phase 3 (population CEU). 
Table 2 Distribution of alleles and genotypes of rs334558 in groups of remitters and non-remitters (selective serotonin inhibitors only)

\begin{tabular}{lllll}
\hline Polymorphism & $\begin{array}{l}\text { Genotype, } \\
\text { allele }\end{array}$ & $\begin{array}{l}\text { Remitters } \\
(\%)\end{array}$ & $\begin{array}{l}\text { Non- } \\
\text { remitters (\%) }\end{array}$ & $\begin{array}{l}\text { Hardy-Weinberg } \\
\text { equilibrium }\left(\chi^{2}, \boldsymbol{p}\right)\end{array}$ \\
\hline rs334558 & T/T & 33.7 & 14.3 & $\chi_{1}^{2}=0.001, p_{1}=0.975 ;$ \\
& C/T & 48.8 & 52.4 & $\chi_{2}^{2}=0.159, p_{2}=0.690$ \\
& C/C & 17.4 & 33.3 & $\chi^{2}=4.248, p=0.120$ \\
& T & 58.1 & 40.5 & \\
& C & 41.9 & 59.5 & \\
\hline
\end{tabular}

Note: Numbers I and 2 in subscript represent group of remitters and group of non-remitters, respectively.

The present study reports association of remission following pharmacological antidepressant treatment with allele $\mathrm{T}$ of rs334558, but a previous study reported that this allele is associated with resistance to antidepressant medication ${ }^{53}$ and others reported association of this allele with poorer response to lithium treatment. ${ }^{54-56}$ In all these studies, contribution of other molecular factors, including different genetic and epigenetic backgrounds, was not taken account of. Treatment-resistant depression is a phenomenon far from being fully understood, with multiple molecular factors likely contributing to its development. ${ }^{2,65,66}$ Different genetic and epigenetic backgrounds may modulate the influence of rs334558 on the response to drug treatment. In particular, the genetic landscape in different human populations could explain the changing direction of association depending on the population studied. In fact, allele frequencies of this functional variant change drastically in different human populations: according to data in the 1000 Genomes Project, the frequency of allele $\mathrm{T}$ goes from $67.1 \%$ in populations with European ancestry to $5.9 \%$ in populations with African ancestry (https://www.ncbi.nlm.nih.gov/projects/SNP/ snp ss.cgi? ss $=$ ss 1305845106$).$ This may mean that different genetic factors interact with this functional variant in different human populations. It is thus possible that in our cohort a different genetic and/or epigenetic background defines the different outcome in the presence of allele $\mathrm{T}$, namely remission following pharmacological treatment. Further examples of extensively investigated functional candidate genes, whose association with mental disorders and treatment response changes in different populations, are the brain-derived neurotrophic factor, encoded by $B D N F,{ }^{67}$ and the serotonin transporter, encoded by SLC $6 A 4 .^{68}$

Because drug treatment of depressive disorders, due to their extensive heterogeneity, seems to be better viewed from the standpoint of personalized medicine, it is important to define actionable molecular biomarkers that will help predict treatment response. ${ }^{10-19}$ The functional variant rs 334558 could be such a genetic and pharmacogenetic biomarker for a number of phenotypes, including mood disorders, schizophrenia and neurodegenerative disorders. This biomarker could eventually be used in clinical settings, together with other relevant multidimensional data, such as levels of $G S K 3 B$ 's promoter methylation or levels of expression of downstream targets of this gene, analyzed by machine-learning algorithms, ${ }^{69-71}$ in order to determine the precise molecular etiopathological processes and recommend the appropriate personalized medicine-driven treatment..$^{27,72-75}$

It is important to note that the personalized medicine approach, in the context of treatment of depressive disorders in particular, will be substantially complex because the task of determining actionable biomarkers will require an important volume of functional studies referring to treatment response. Multiplex functional studies ${ }^{76}$ should be the most appropriate way to proceed, given the substantial volume of data involved. In addition, personalized medicine applications in clinic, including pharmacogenetic testing, have not yet been convincingly shown to be cost-effective, ${ }^{73,74}$ so more prospective studies evaluating cost-effectiveness and development of new cost-effective treatment schemes are needed.

\section{Conclusion}

This study reported data, suggesting the role of the functional variant rs334558 as a pharmacogenetic biomarker for depressive disorders in the context of personalized medicine-driven treatment. The results of genotyping should be used in conjunction with other relevant biomarkers because the phenotypic outcome in the case of this potential biomarker depends on other genetic and epigenetic factors that modulate it.

\section{Acknowledgments}

This work was in part accomplished within the framework of the Competitiveness Enhancement Program of Tomsk Polytechnic University, and was supported by the Russian Foundation for Basic Research, grant \#17-29-02205. 


\section{Disclosure}

The authors report no conflicts of interest in this work.

\section{References}

1. GBD 2015 Disease and Injury Incidence and Prevalence Collaborators. Global, regional, and national incidence, prevalence, and years lived with disability for 310 diseases and injuries, 1990-2015: a systematic analysis for the Global Burden of Disease Study 2015. Lancet. 2016;388(10053):1545-1602.

2. Akil H, Gordon J, Hen R, et al. Treatment resistant depression: a multi-scale, systems biology approach. Neurosci Biobehav Rev. 2018;84:272-288.

3. Smoller JW. The genetics of stress-related disorders: PTSD, depression, and anxiety disorders. Neuropsychopharmacology. 2016;41(1):297-319.

4. Mullins N, Lewis CM. Genetics of depression: progress at last. Curr Psychiatry Rep. 2017;19(8):43.

5. Sullivan PF, Daly MJ, O'Donovan M. Genetic architectures of psychiatric disorders: the emerging picture and its implications. Nat Rev Genet. 2012;13(8):537-551.

6. Kendler KS, Gatz M, Gardner CO, Pedersen NL. A Swedish national twin study of lifetime major depression. Am J Psychiatry. 2006;163(1):109-114.

7. Sullivan PF, Neale MC, Kendler KS. Genetic epidemiology of major depression: review and meta-analysis. Am J Psychiatry. 2000;157(10):1552-1562.

8. Pishva E, Rutten BPF, van den Hove D. DNA methylation in major depressive disorder. Adv Exp Med Biol. 2017;978:185-196.

9. Deussing JM, Jakovcevski M. Histone modifications in major depressive disorder and related rodent models. Adv Exp Med Biol. 2017;978:169-183.

10. Redei EE, Mehta NS. The promise of biomarkers in diagnosing major depression in primary care: the present and future. Curr Psychiatry Rep. 2015;17(8):601.

11. Huang TL, Lin CC. Advances in biomarkers of major depressive disorder. Adv Clin Chem. 2015;68:177-204.

12. Alhajji L, Nemeroff CB. Personalized medicine and mood disorders. Psychiatr Clin North Am. 2015;38(3):395-403.

13. Fabbri C, Hosak L, Mossner R, et al. Consensus paper of the WFSBP Task Force on Genetics: genetics, epigenetics and gene expression markers of major depressive disorder and antidepressant response. World J Biol Psychiatry. 2017;18(1):5-28.

14. Smoller JW. Psychiatric genetics and the future of personalized treatment. Depress Anxiety. 2014;31(11):893-898.

15. Alda M. Personalized psychiatry: many questions, fewer answers. J Psychiatry Neurosci. 2013;38(6):363-365.

16. Ozomaro U, Wahlestedt $\mathrm{C}$, Nemeroff $\mathrm{CB}$. Personalized medicine in psychiatry: problems and promises. BMC Med. 2013;11:132.

17. Wium-Andersen IK, Vinberg M, Kessing LV, McIntyre RS. Personalized medicine in psychiatry. Nord J Psychiatry. 2017;71(1):12-19.

18. Demkow U, Wolanczyk T. Genetic tests in major psychiatric disordersintegrating molecular medicine with clinical psychiatry-why is it so difficult? Transl Psychiatry. 2017;7(6):e1151.

19. Loonen AJ, Stahl SM. Functional psychopharmacology is the way to go in pharmacotherapy for psychiatric disorders. Acta Psychiatr Scand. 2010;122(6):435-437.

20. Cuthbert BN. Research domain criteria: toward future psychiatric nosologies. Dialogues Clin Neurosci. 2015;17(1):89-97.

21. Morris SE, Cuthbert BN. Research domain criteria: cognitive systems, neural circuits, and dimensions of behavior. Dialogues Clin Neurosci. 2012;14(1):29-37.

22. Insel T, Cuthbert B, Garvey M, et al. Research domain criteria (RDoC): toward a new classification framework for research on mental disorders. Am J Psychiatry. 2010;167(7):748-751.

23. Thase ME, Schwartz TL. Choosing medications for treatmentresistant depression based on mechanism of action. J Clin Psychiatry. 2015;76(6):720-727; quiz 727.
24. Lin E, Lane HY. Genome-wide association studies in pharmacogenomics of antidepressants. Pharmacogenomics. 2015;16(5):555-566.

25. Fabbri C, Serretti A. Pharmacogenetics of major depressive disorder: top genes and pathways toward clinical applications. Curr Psychiatry Rep. 2015;17(7):50.

26. Fabbri C, Crisafulli C, Calabro M, Spina E, Serretti A. Progress and prospects in pharmacogenetics of antidepressant drugs. Expert Opin Drug Metab Toxicol. 2016;12(10):1157-1168.

27. Ramos M, Berrogain C, Concha J, Lomba L, Garcia CB, Ribate MP. Pharmacogenetic studies: a tool to improve antidepressant therapy. Drug Metab Pers Ther. 2016;31(4):197-204.

28. Losenkov IS, Vyalova NM, Simutkin GG, Bokhan NA, Ivanova SA. An association of $A K T 1$ gene polymorphism with antidepressant treatment response. World J Biol Psychiatry. 2016;17(3):239-242.

29. Lisoway AJ, Zai CC, Tiwari AK, Kennedy JL. DNA methylation and clinical response to antidepressant medication in major depressive disorder: a review and recommendations. Neurosci Lett. 2018;669:14-23.

30. Beaulieu JM, Gainetdinov RR, Caron MG. Akt/GSK3 signaling in the action of psychotropic drugs. Annu Rev Pharmacol Toxicol. 2009;49:327-347.

31. Freyberg Z, Ferrando SJ, Javitch JA. Roles of the Akt/GSK-3 and Wnt signaling pathways in schizophrenia and antipsychotic drug action. $A m$ J Psychiatry. 2010;167(4):388-396.

32. Emamian ES. AKT/GSK3 signaling pathway and schizophrenia. Front Mol Neurosci. 2012;5:33.

33. Losenkov IS, Ivanova SA, Vyalova NA, Simutkin GG, Bokhan NA. Proteins of the $A k t 1 / G S K-3 \beta$ signaling pathway in peripheral blood mononuclear cells of patients with affective disorders. Neurochem $J$. 2014;8(3):208-213.

34. Emamian ES, Hall D, Birnbaum MJ, Karayiorgou M, Gogos JA. Convergent evidence for impaired $A K T 1$-GSK3beta signaling in schizophrenia. Nat Genet. 2004;36(2):131-137.

35. Pereira PA, Bicalho MA, de Moraes EN, et al. Genetic variant of $A K T 1$ and $A K T I P$ associated with late-onset depression in a Brazilian population. Int J Geriatr Psychiatry. 2014;29(4):399-405.

36. Doble BW, Woodgett JR. GSK-3: tricks of the trade for a multi-tasking kinase. J Cell Sci. 2003;116(Pt 7):1175-1186.

37. Logan CY, Nusse R. The Wnt signaling pathway in development and disease. Annu Rev Cell Dev Biol. 2004;20:781-810.

38. Lovestone S, Killick R, Di Forti M, Murray R. Schizophrenia as a GSK-3 dysregulation disorder. Trends Neurosci. 2007;30(4):142-149.

39. Li X, Jope RS. Is glycogen synthase kinase-3 a central modulator in mood regulation? Neuropsychopharmacology. 2010;35(11):2143-2154.

40. Singh KK. An emerging role for Wnt and GSK3 signaling pathways in schizophrenia. Clin Genet. 2013;83(6):511-517.

41. Dachtler J, Elliott C, Rodgers RJ, Baillie GS, Clapcote SJ. Missense mutation in DISC1 C-terminal coiled-coil has GSK3beta signaling and sex-dependent behavioral effects in mice. Sci Rep. 2016;6:18748.

42. Levchenko A, Davtian S, Freylichman O, Zagrivnaya M, Kostareva A, Malashichev Y. Beta-catenin in schizophrenia: possibly deleterious novel mutation. Psychiatry Res. 2015;228(3):843-848.

43. de Ligt J, Willemsen MH, van Bon BW, et al. Diagnostic exome sequencing in persons with severe intellectual disability. N Engl J Med. 2012;367(20):1921-1929.

44. Kharbanda M, Pilz DT, Tomkins S, et al. Clinical features associated with CTNNB1 de novo loss of function mutations in ten individuals. Eur J Med Genet. 2017;60(2):130-135.

45. Li N, Xu Y, Li G, et al. Exome sequencing identifies a de novo mutation of CTNNB1 gene in a patient mainly presented with retinal detachment, lens and vitreous opacities, microcephaly, and developmental delay: case report and literature review. Medicine (Baltimore). 2017;96(20):e6914.

46. O'Roak BJ, Vives L, Girirajan S, et al. Sporadic autism exomes reveal a highly interconnected protein network of de novo mutations. Nature. 2012;485(7397):246-250.

47. Tucci V, Kleefstra T, Hardy A, et al. Dominant beta-catenin mutations cause intellectual disability with recognizable syndromic features. J Clin Invest. 2014;124(4):1468-1482. 
48. Mao Y, Ge X, Frank CL, et al. Disrupted in schizophrenia 1 regulates neuronal progenitor proliferation via modulation of $G S K 3$ beta/betacatenin signaling. Cell. 2009;136(6):1017-1031.

49. Kwok JB, Hallupp M, Loy CT, et al. GSK3B polymorphisms alter transcription and splicing in Parkinson's disease. Ann Neurol. 2005;58(6):829-839.

50. Hamilton M. A rating scale for depression. J Neurol Neurosurg Psychiatry. 1960;23:56-62.

51. Mateo I, Vazquez-Higuera JL, Sanchez-Juan P, et al. Epistasis between tau phosphorylation regulating genes (CDK5R1 and GSK-3beta) and Alzheimer's disease risk. Acta Neurol Scand. 2009;120(2):130-133.

52. Park SW, Lee JG, Kong BG, et al. Genetic association of $B D N F$ val66met and GSK-3beta-50T/C polymorphisms with tardive dyskinesia. Psychiatry Clin Neurosci. 2009;63(4):433-439.

53. Tsai SJ, Liou YJ, Hong CJ, Yu YW, Chen TJ. Glycogen synthase kinase-3beta gene is associated with antidepressant treatment response in Chinese major depressive disorder. Pharmacogenomics J. 2008;8(6):384-390.

54. Benedetti F, Bollettini I, Barberi I, et al. Lithium and GSK3-beta promoter gene variants influence white matter microstructure in bipolar disorder. Neuropsychopharmacology. 2013;38(2):313-327.

55. Lin YF, Huang MC, Liu HC. Glycogen synthase kinase 3 beta gene polymorphisms may be associated with bipolar I disorder and the therapeutic response to lithium. J Affect Disord. 2013;147(1-3):401-406.

56. Benedetti F, Poletti S, Radaelli D, et al. Lithium and GSK-3beta promoter gene variants influence cortical gray matter volumes in bipolar disorder. Psychopharmacology (Berl). 2015;232(7):1325-1336.

57. Benedetti F, Poletti S, Radaelli D, et al. Temporal lobe grey matter volume in schizophrenia is associated with a genetic polymorphism influencing glycogen synthase kinase 3-beta activity. Genes Brain Behav. 2010;9(4):365-371.

58. Benedetti F, Bernasconi A, Lorenzi C, et al. A single nucleotide polymorphism in glycogen synthase kinase 3-beta promoter gene influences onset of illness in patients affected by bipolar disorder. Neurosci Lett. 2004;355(1-2):37-40.

59. Benedetti F, Serretti A, Colombo C, Lorenzi C, Tubazio V, Smeraldi E. A glycogen synthase kinase 3-beta promoter gene single nucleotide polymorphism is associated with age at onset and response to total sleep deprivation in bipolar depression. Neurosci Lett. 2004;368(2):123-126.

60. Kettunen P, Larsson S, Holmgren S, et al. Genetic variants of GSK3B are associated with biomarkers for Alzheimer's disease and cognitive function. J Alzheimers Dis. 2015;44(4):1313-1322.

61. Galimberti D, Macmurray J, Scalabrini D, et al. GSK3beta genetic variability in patients with multiple sclerosis. Neurosci Lett. 2011;497(1):46-48.

62. Lin Q, Cao YP, Gao J. Common polymorphisms in the GSK3beta gene may contribute to the pathogenesis of Alzheimer disease: a metaanalysis. J Geriatr Psychiatry Neurol. 2015;28(2):83-93.
63. Liu S, Wang L, Sun N, et al. The gender-specific association of rs 334558 in GSK3beta with major depressive disorder. Medicine (Baltimore). 2017;96(3):e5928.

64. Tang H, Shen N, Jin H, Liu D, Miao X, Zhu LQ. GSK-3beta polymorphism discriminates bipolar disorder and schizophrenia: a systematic meta-analysis. Mol Neurobiol. 2013;48(3):404-411.

65. Kim YK, Na KS. Role of glutamate receptors and glial cells in the pathophysiology of treatment-resistant depression. Prog Neuropsychopharmacol Biol Psychiatry. 2016;70:117-126.

66. Kulikov AV, Gainetdinov RR, Ponimaskin E, Kalueff AV, Naumenko VS, Popova NK. Interplay between the key proteins of serotonin system in SSRI antidepressants efficacy. Expert Opin Ther Targets. 2018;22(4):319-330.

67. Notaras M, Hill R, van den Buuse M. A role for the BDNF gene Val66Met polymorphism in schizophrenia? A comprehensive review. Neurosci Biobehav Rev. 2015;51:15-30.

68. Mrazek DA, Rush AJ, Biernacka JM, et al. SLC6A4 variation and citalopram response. Am J Med Genet B Neuropsychiatr Genet. 2009; 150B(3):341-351.

69. Adams RA, Huys QJ, Roiser JP. Computational psychiatry: towards a mathematically informed understanding of mental illness. J Neurol Neurosurg Psychiatry. 2016;87(1):53-63.

70. Hahn T, Nierenberg AA, Whitfield-Gabrieli S. Predictive analytics in mental health: applications, guidelines, challenges and perspectives. Mol Psychiatry. 2017;22(1):37-43.

71. Huys QJ, Maia TV, Frank MJ. Computational psychiatry as a bridge from neuroscience to clinical applications. Nat Neurosci. 2016;19(3):404-413.

72. Nassan M, Nicholson WT, Elliott MA, Rohrer Vitek CR, Black JL, Frye MA. Pharmacokinetic pharmacogenetic prescribing guidelines for antidepressants: a template for psychiatric precision medicine. Mayo Clin Proc. 2016;91(7):897-907.

73. Rosenblat JD, Lee Y, McIntyre RS. Does pharmacogenomic testing improve clinical outcomes for major depressive disorder? A systematic review of clinical trials and cost-effectiveness studies. J Clin Psychiatry. 2017;78(6):720-729.

74. Peterson K, Dieperink E, Anderson J, Boundy E, Ferguson L, Helfand M. Rapid evidence review of the comparative effectiveness, harms, and cost-effectiveness of pharmacogenomics-guided antidepressant treatment versus usual care for major depressive disorder. Psychopharmacology (Berl). 2017;234(11):1649-1661.

75. Madan A, Walker CR, Weinstein B, Fowler JC. Pharmacogenomics in practice: a case report of personalized inpatient psychiatric care. Pharmacogenomics. 2015;16(5):433-439.

76. Starita LM, Ahituv N, Dunham MJ, et al. Variant interpretation: functional assays to the rescue. Am J Hum Genet. 2017;101(3):315-325.
Pharmacogenomics and Personalized Medicine

\section{Publish your work in this journal}

Pharmacogenomics and Personalized Medicine is an international, peerreviewed, open access journal characterizing the influence of genotype on pharmacology leading to the development of personalized treatment programs and individualized drug selection for improved safety, efficacy and sustainability. This journal is indexed on the American Chemical
Society's Chemical Abstracts Service (CAS). The manuscript management system is completely online and includes a very quick and fair peer-review system, which is all easy to use. Visit http://www.dovepress com/testimonials.php to read real quotes from published authors. 